\title{
Identification of likely foraging habitat of pelagic loggerhead sea turtles (Caretta caretta) in the North Atlantic through analysis of telemetry track sinuosity
}

\author{
Abigail L. McCarthy ${ }^{\mathrm{a}, *}$, Selina Heppell ${ }^{\mathrm{a}}$, Francois Royer $^{\mathrm{b}}$, Carla Freitas ${ }^{\mathrm{c}, \mathrm{d}}$, Thomas Dellinger $^{\mathrm{c}}$ \\ a Oregon State University, Fisheries and Wildife Department, Corvallis, OR 97331-3803, USA \\ ${ }^{\mathrm{b}}$ University of New Hampshire, Large Pelagics Research Lab, Durham, NH 03824, USA \\ ${ }^{\mathrm{c}}$ Laboratório de Biologia Marinha e Oceanografia, Universidade da Madeira, Estação de Biologia Marinha do Funchal, Cais do Carvão - Promenade da Orla Marítima, \\ P-9000-107 Funchal-Madeira, Portugal \\ ${ }^{\mathrm{d}}$ Norweigan Polar Institute, Polar Environmental Center, N-9296 Tronso, Norway
}

\section{A R T I C L E I N F O}

\section{Article history:}

Received 6 March 2008

Received in revised form 3 September 2009

Accepted 10 April 2010

Available online 28 April 2010

\begin{abstract}
A B S T R A C T
Changes in the behavior of individual animals in response to environmental characteristics can provide important information about habitat preference, as well as the relative risk that animals may face based on the amount of time spent in hazardous areas. We analyzed movement and habitat affinities of ten loggerhead turtles (Caretta caretta) tagged with satellite transmitters in the spring and fall of 1998 near Madeira, Portugal for periods of 2-10 months. We analyzed the behavior of these individuals in relation to the marine environment they occupied. As a measure of behavior we calculated the straightness index (SI), the ratio of the displacement of the animal to the total distance traveled, for individual weekly segments of the 10 tracks. We then extracted information about chlorophyll $a$ concentration, sea-surface temperature (SST), bathymetry, and geostrophic current of the ocean in a $20-\mathrm{km}$ buffer surrounding the tracks, and examined their relationship to the straightness index using generalized linear models. Chlorophyll $a$ value, bathymetry and SST were significantly related to the straightness index of the tracks of all ten animals, as was the circular standard deviation of the geostrophic current (Wald's test: $p=$ $0.001, p=0.008, p=0.025$, and $p=0.049$, respectively). We found a significant negative relationship between straightness index and chlorophyll, and positive relationships with ocean depth and SST indicating that animals are spending more time and searching more thoroughly in areas with high chlorophyll concentrations and in areas that are shallower, while moving in straight paths through very warm areas. We also found a positive relationship between straightness index and the circular standard deviation of surrounding geostrophic currents suggesting that these turtles are more likely to move in a straight line when in the presence of diffuse, less-powerful currents. Based on these relationships, we propose that conservation planning to reduce overlap of turtles with fishing operations should take into account the locations of bathymetric features such as seamounts and upwelling locations where chlorophyll concentrations are high. This analysis is an effective way to characterize areas of high-use habitat for satellitetagged marine vertebrates, and allows for comparisons of these characteristics between species and among individuals.
\end{abstract}

Published by Elsevier Ltd.

\section{Introduction}

Because of the transitory nature of ocean habitat for marine turtles and other wide-ranging pelagic vertebrates, prioritizing conservation areas for these animals is extremely difficult. Defining the oceanographic characteristics of high-use regions is a step towards the ultimate goal of effective conservation planning in the pelagic ocean. The combination of high-resolution satellite-tracking data

\footnotetext{
* Corresponding author at: National Oceanic and Atmospheric Administration, National Marine Fisheries Service, 7600 Sand Point Way N.E., Building 4, Seattle, WA 98115, USA. Tel.: +1 2065264129.

E-mail address: Abigail.McCarthy@noaa.gov (A.L. McCarthy).
}

with remotely sensed oceanographic data on the same temporal and spatial scales makes it possible to identify preferred habitat for highly migratory pelagic vertebrates, in this case loggerhead turtles, by analyzing the movement patterns of individual animals in conjunction with their immediate oceanic environment (Baumgartner and Mate, 2005; Seminoff et al., 2008). This quantitative approach enables comparison of habitat use among individuals of a single species and between different species, unlike more qualitative methods of habitat assessment. When we more fully understand the relationship between individual behavior and oceanography, we can only then begin to understand the potential impacts of changing ocean circulation on foraging and migratory behavior of whole populations on a global scale (Barbraud and Weimerskirch, 2001; Wanless et al., 2007). 
Studies of the marine habitat associations of large pelagic vertebrates show that animals aggregate at shelf breaks, upwelling regions, and oceanic fronts, presumably due to increased forage availability in these highly dynamic areas (Hyrenbach et al., 2000; Yen et al., 2004; Eckert, 2006; Hawkes et al., 2006; Polovina et al., 2006). However, only a few studies directly link the observed behavior of tracked animals to oceanographic characteristics in a quantitative manner (Pinaud and Weimerskirch, 2007; Freitas et al., 2008). Studies of marine turtles in particular have generally classified regions of the ocean as high-use habitat based on qualitative classification of residence time of tracked animals, and in some cases diving behavior, or aggregated tracks from large numbers of animals (Polovina et al., 2004; James et al., 2005, 2006; Eckert, 2006; Hawkes et al., 2006; Kobayashi et al., 2008). In this study, we seek to fill a gap in the understanding of loggerhead turtle ecology by linking the behavior, in particular the track sinuosity, of animals to their immediate marine environment. Through this detailed analysis of the tracks of ten different individuals tagged during different seasons we elucidate the differences between the oceanographic characteristics of areas that animals simply passed through and those in which they exhibited typical foraging behavior.

Behavioral ecology methods from the terrestrial world, when coupled with oceanographic remote sensing data, are useful for understanding how marine turtle movement patterns relate to the characteristics of the ocean through which they travel. We know that in both marine and terrestrial systems, an increase in turn angle and increasing "sinuosity" of tracks often accompany foraging (Bovet and Benhamou, 1988; Hill et al., 2000; Maerell et al., 2002; Newlands et al., 2004; Gutenkunst et al., 2007). The ratio of an individual's displacement to the total distance traveled, called the straightness index, indicates the relative sinuosity of an animal's path (Hull et al., 1997; Benhamou, 2004) which is an effective measure of local search efforts. The straightness index of individual segments of a turtle's track on a daily or weekly basis is an indicator of how carefully an individual has searched a given area. This measure of search effort can then be related to the surrounding marine habitat to improve our understanding of what constitutes a foraging area, or an area of intensified searching, for a given animal or group of animals.

In this study, we investigated how the behavior of individual loggerhead turtles, as measured by weekly straightness index, is related to marine habitat in the eastern North Atlantic. We examined the relationship between straightness index as a measure of the behavior of these individuals relative to various habitat parameters, namely bathymetry, geostrophic currents, chlorophyll $a$ concentration, and sea-surface temperature. This analysis differs from other studies of pelagic marine turtles in that it compares a suite of marine habitat variables to a quantitative measure of animal behavior, and it differentiates between presence of the animal in the water and intensified search of an area by an individual. By breaking tracks down into weekly segments, and relating the sinuosity of those segments to the oceanographic characteristics of the water mass that the animal was occupying at that time, we can tell how the changing environment is linked with variability in the animal's behavior.

\section{Methods}

\subsection{Satellite tag deployment}

ARGOS satellite tags (model SDR-T10 from Wildlife Computers, weight $360 \mathrm{~g}$ on air) were attached to ten juvenile loggerhead sea turtles in late May $(n=5)$ and early September $(n=5)$ of 1998 (see Table 1 ). These two groups of turtles were hand captured from a boat off the south coast of the island of Madeira. Turtles were brought to land, tagged and then later released from boats on average $7.6 \pm 2.7$ days after capture. Tags were attached as backpacks during captivity following Balazs et al. (1996), and data were recorded for the entire life of the tag, or of the tagged animal (Dellinger and Freitas, 1999).

\subsection{Kalman filter application to location data}

Because of location errors inherent to Doppler telemetry, it is necessary to filter ARGOS location data (ARGOS, 1996; Hays et al., 2001; Vincent et al., 2002; Jonsen et al., 2005) and regularize them in time. This was achieved via Kalman filtering and smoothing (Royer and Lutcavage, 2008), assuming a random walk for the turtle's movement model (Sibert et al., 2003). To limit the influence of outliers, a robust estimator was designed using Expectation-Maximization (Roweis and Ghahramani, 1999). The EM involves the successive applications of the Kalman filter and smoother equations (Expectations step) followed by an estimation of each point's probability of being an outlier. Hence, probable outliers are given a lower weight, and the iterations are continued until the solution track has converged. We used a value of 0.01 for the outliers $(P)$, a value of $100 \mathrm{~km}^{2}$ per day for the diffusion parameter $(D)$, and a value of $12 \mathrm{~h}$ for the regularization time step, as the latter was similar to the actual period between successive independent ARGOS locations. All calculations were conducted using Matlab code; available upon request (Royer, 2008). More details about filtering and smoothing ARGOS locations can be found in Royer and Lutcavage (2008).

\subsection{Track straightness index}

We calculated the straightness index (SI; (Batschelet, 1981; Benhamou, 2004) of each weekly segment of turtle track by dividing the straight-line distance, or the displacement of the animal, by the total distance traveled by the animal during that week. We chose to use weekly segments of track because we used weekly averages of oceanographic data. For a comparison to be made between the animal trajectory and the environmental conditions, the time scales of the two types of data need to be the same.

The straightness index of a segment of track is assumed to be representative of the search effort of the individual animal during that week (Fig. 1). If the animal moves from point A to point B via the solid path, then the straightness index is the ratio of the dashed line to the solid black line; thus, the value for SI ranges from near zero, if the animal moved an infinite distance between start and end-points, to a value of 1 , if the animal moved in a perfectly straight line (Fig. 1). For the purpose of this study, point $A$ and point $B$ represent the start and end locations of a full week of track data.

To assure that all weekly straightness index values represented the displacement of the animal over a period of seven days, we did not include track segments with three or fewer original ARGOS locations in our analysis. Missing satellite location values led to a straight line interpolation between points by the Kalman filter, so there were several segments in tracks that did not represent actual behavior. The removal of weeks with three or fewer original locations reduced the sample size of weekly track segments that were included in the analysis from 345 total weekly segments to 305 ; remaining weekly segments contained $21.5 \pm 13.3$ (SD) location estimates.

\subsection{Satellite oceanography data}

We used Advanced Very-High Resolution Radiometer (AVHRR) Pathfinder Version 5.0 (4-km resolution, 8-day mean) sea-surface temperature data from the National Ocean Data Center (NODC). 
Table 1

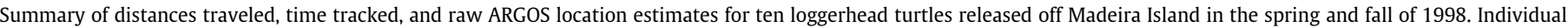
animals are listed in order of number of ARGOS estimates.

\begin{tabular}{|c|c|c|c|c|c|c|}
\hline Turtle ID & Turtle name & Release date & Total days tracked & Total distance traveled $(\mathrm{km})$ & Fall or spring release & ARGOS location estimates \\
\hline 2 & Lidia & 4/1/1998 & 274 & 4539 & $\mathrm{~S}$ & 1329 \\
\hline 1 & Delia & $5 / 18 / 1998$ & 278 & 7394 & $\mathrm{~S}$ & 1174 \\
\hline 6 & Isabel & 9/10/1998 & 312 & 5276 & $\mathrm{~F}$ & 1069 \\
\hline 8 & Samina & 9/10/1998 & 275 & 4267 & $\mathrm{~F}$ & 965 \\
\hline 7 & Maria & $5 / 27 / 1998$ & 349 & 5263 & $\mathrm{~S}$ & 920 \\
\hline 5 & Helena & $9 / 10 / 1998$ & 337 & 6133 & $\mathrm{~F}$ & 879 \\
\hline 3 & Carla & $5 / 27 / 1998$ & 160 & 3371 & $\mathrm{~S}$ & 621 \\
\hline 4 & Magda & $5 / 18 / 1998$ & 109 & 2434 & $\mathrm{~S}$ & 583 \\
\hline 9 & Sofia & 9/10/1998 & 123 & 1963 & $\mathrm{~F}$ & 521 \\
\hline 10 & Tamia & 9/10/1998 & 58 & 919 & $\mathrm{~F}$ & 139 \\
\hline
\end{tabular}

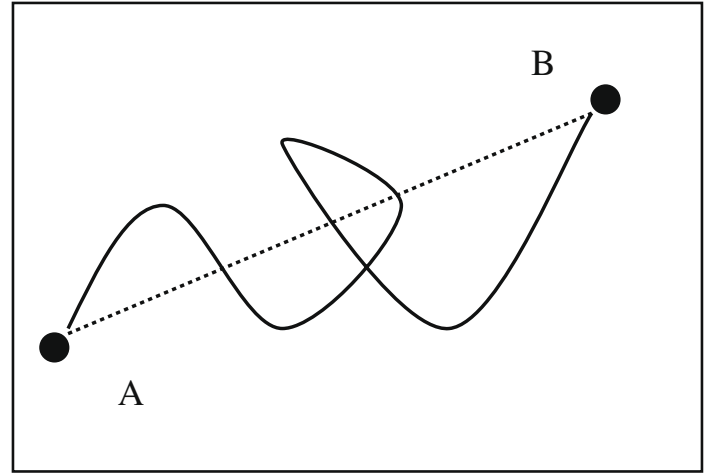

Fig. 1. Schematic drawing of straightness index (SI). Point A represents the start of the track for a given week. Point B represents the end of the track for that week. The straight line is the total distance traveled while the sinuous line represents the animal's path.

We included pixels with quality flags of levels 3-7 in the analysis. We used chlorophyll $a$ data from the NASA Goddard Space Flight Center (GSFC) Sea-viewing Wide Field-of-view Sensor (SeaWiFS) level $3 \mathrm{ftp}$ site, at $9 \mathrm{~km}, 8$-day resolution. We used the General Bathymetric Chart of the Oceans (GEBCO) $5^{\prime \prime}$ gridded bathymetry data, available from the British Oceanographic Data Centre (http:// www.bodc.ac.uk).

We calculated the geostrophic currents using data from the AVISO live access server (www.las.aviso.oceanobs.com/las/servlets/dataset). We used the 7-day, weighted mean AVISO data with 1/3-degree resolution. Because geostrophic current data are not available online in readily accessible format for 1998-1999, we took several steps to obtain the $u$ and $v$ components of geostrophic current velocity vectors. The first step was to calculate the mean dynamic topography (MDT) to be used as a basis for further calculations. We did this by subtracting the sea-level anomalies (SLA) for a given day from the absolute dynamic topography (MADT) available for the same day; this produced the mean dynamic topography (MDT). We performed this procedure using data from after 2001, when MADT data were available on the LAS. The next step to calculate geostrophic currents for 1998-1999 was to add the SLA for specific dates of interest to the MDT calculated above, to get the MADT for the appropriate dates. Finally, we applied the geostrophic equation to the MADT to get the $u$ and $v$ velocities $(\mathrm{m} / \mathrm{s})$ of the geostrophic current at 1/3-degree resolution (Bearman, 2001).

\subsection{Oceanographic data extraction}

To obtain oceanographic data for analysis, we created elliptical buffers around the section of track of interest (Fig. 2). Buffers were $20 \mathrm{~km}$ from either side of the track; a total of $40 \mathrm{~km}$ wide. We chose a buffer distance of twenty kilometers to ensure that we were able to extract at least one pixel of the gridded AVISO data, and several pixels of both SST and chlorophyll $a$ data per track segment. We used this procedure to extract all oceanographic data for the weekly track segments and summarized data from within the buffers by calculating both mean and variance of the pixels included in the buffer, excluding pixels removed due to cloud masks or other errors.

The analysis of the weekly geostrophic current data was threefold. First, we calculated the mean angle of travel for the individual animal for the week of interest, and the circular standard deviation of that mean angle using circular statistics (Batschelet, 1981). The circular standard deviation $(s)$ is analogous to the standard deviation of linear data. Then, we calculated the mean angular direction and circular standard deviation of the current using the same statistical method. Finally, we compared these two mean directions to determine whether or not animals were moving in the same direction as geostrophic currents.

In order to find the mean travel direction for a week of tracking locations, we calculated the bearing $(a)$ between each consecutive location within the track segment of interest. We then calculated the mean angle of movement among those bearings, using the following equations described in Batschelet (1981) and White and Garrott (1990):

$\bar{X}=\frac{1}{n} \sum_{i=1}^{n} \cos a_{i}$

$\bar{Y}=\frac{1}{n} \sum_{i=1}^{n} \sin a_{i}$

$r=\sqrt{\bar{X}^{2}+\bar{Y}^{2}}$

where $a_{i}$ is the bearing of the $i$ th track segment of that weekly track, $n$ the number of segments for that week, $\bar{Y}$ is the mean relative distance traveled in the $Y$-direction, $\bar{X}$ is the mean relative distance traveled in the $X$-direction, and $r$ is a measure of the concentration of angles. The circular standard deviation, $s$, is calculated using:

$S=\frac{180}{\pi} \sqrt{(-2 \ln r)}$.

We repeated this procedure on the current vectors included in the buffer around each weekly track segment (Fig. 2). We calculated angular direction and magnitude of individual vectors from the $u$ and $v$ components of the current vectors, converted that angle from mathematic convention to oceanographic convention (Smith et al., 1999), and applied Eqs. (1)-(4) to calculate the angular direction of the current vectors $(a)$, the angular concentration $(r)$, and the circular standard deviation $(s)$. After calculating these quantities for both current direction and animal direction, we calculated Rayleigh's $Z$-statistic: $z=n r^{2}$, to determine whether or not the distribution of the angles differed significantly from a uniform circular distribution (White and Garrott, 1990). If the Z-statistic 


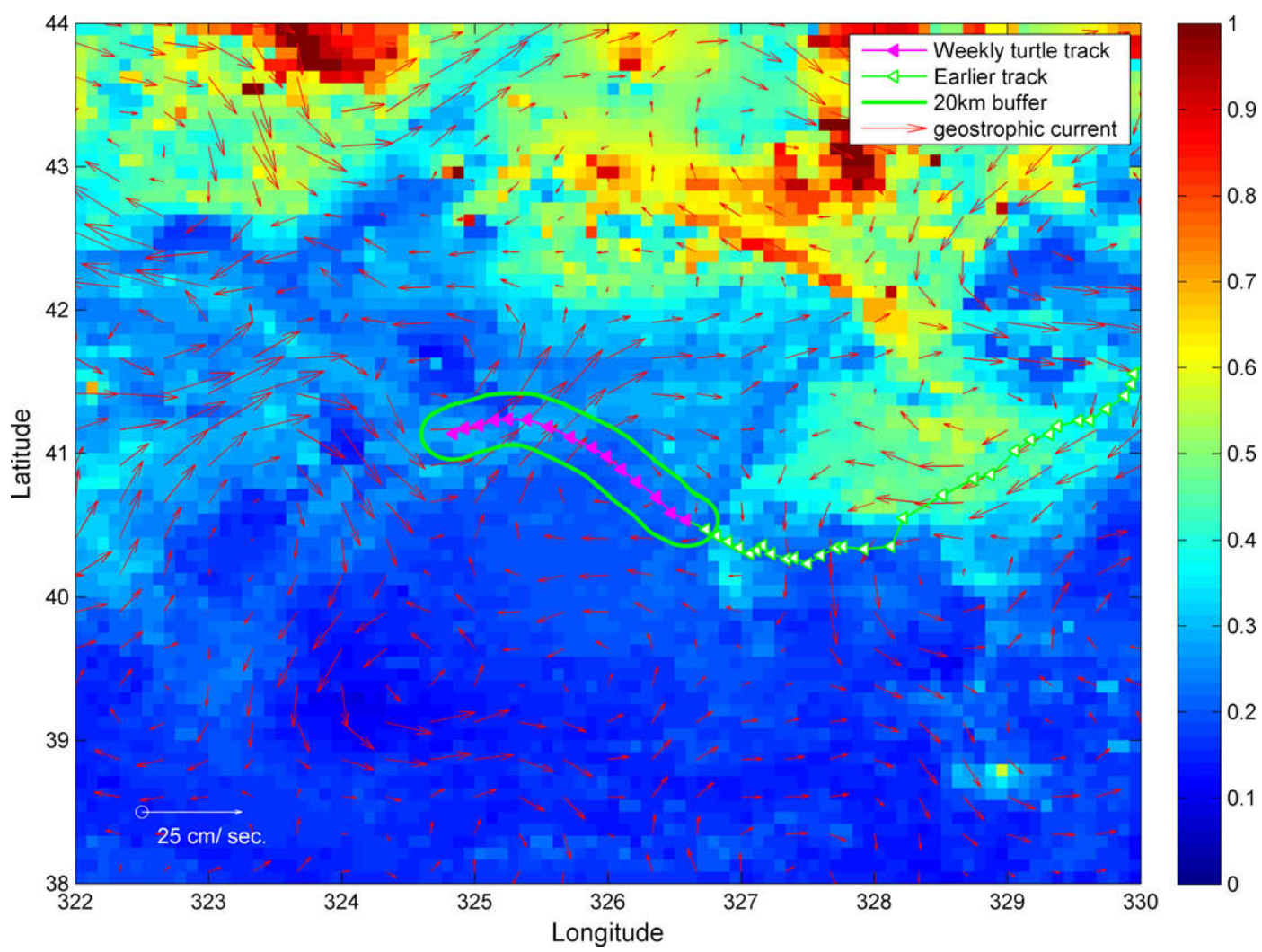

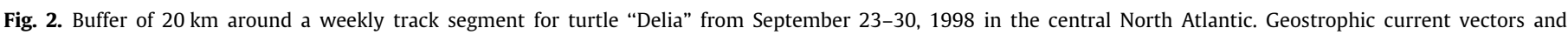

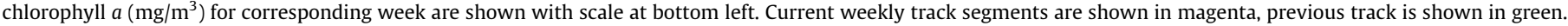

was significant and we could reject the null hypothesis that movement direction was random, we proceeded with testing the modified Rayleigh's Z-test for uniformity vs. a specified mean angle (White and Garrott, 1990; Zar, 1999). We applied this test to determine whether the animal in question was moving with the prevailing geostrophic current for the week in question.

\subsection{Regression model}

We fit a generalized linear model with a binomial distribution and a logit link to the entire set of weekly track data to investigate trends within the dataset. The response variable for this model was the straightness index of the individual segments, straight-track segments were those with a straightness index $(\mathrm{SI})>0.7$, sinuous tracks were those with a $\mathrm{SI} \leqslant 0.7$. This division was based on a frequency histogram of these data, which had a natural break at 0.7 (Fig. 3). Potential predictor variables included a coding variable for individual turtle and time of year (spring or fall release), as well as log-transformed chlorophyll $a$, bathymetry, sea-surface temperature (SST), and two current-related variables. The first current-related variable was the $s$-value, or the circular standard deviation for the current vectors of that given week, and the second was a factor variable that indicated whether or not the animal had been moving with the geostrophic current $(U)$. We performed modelselection between full and reduced models using the Akaike Information Criterion, or AIC (Akaike, 1974).

\section{Results}

\subsection{Loggerhead turtle movements}

The ten tracked animals were released from Madeira in April, May and September of 1998 . Half of the animals moved to the central or northwest Atlantic, and the other half moved southeast towards the coastal area off North Africa (Fig. 4). The animals were tracked for 58-349 days and traveled 919-7394 km during that time (Table 1). Four of the five fall-release animals moved southeast of the release point, and four of the five spring animals moved northwest of the release point.

Visual examination of the weekly track segments and the corresponding oceanographic variables, specifically chlorophyll $a$, shows a pattern of behavior indicating foraging in frontal zones. Animals exhibit the typical foraging behavior (as revealed by more sinuous tracks) when they enter areas with higher chlorophyll $a$, especially when bordered by low chlorophyll $a$ areas; the same pattern is true for areas that are shallower and colder. In areas where the track of an individual is defined as sinuous, the track can be superimposed on remotely sensed chlorophyll $a$ data from the corresponding week, and a clear pattern of increased sinuosity within the higher chlorophyll area can be seen (Fig. 5). All ten tracked individuals showed similar patterns in terms of foraging within and along edges of high chlorophyll $a$ areas, albeit during different times of the year.

\subsection{Model selection}

The full logistic regression model with the binomial indicator of straightness index as a response variable included: a variable coding for the spring or fall release of the animal (spring/fall), a variable coding for the individual animal (turtle), log-transformed chlorophyll a concentration, bathymetry, sea-surface temperature, and circular standard deviation (s). We also examined a reduced model (Reduced model 1) where the spring/fall variable was eliminated, and a final model, which included log-transformed chlorophyll $a$, bathymetry, sea-surface temperature, and $s$ as predictor variables (Table 2 ). When we examined a further 


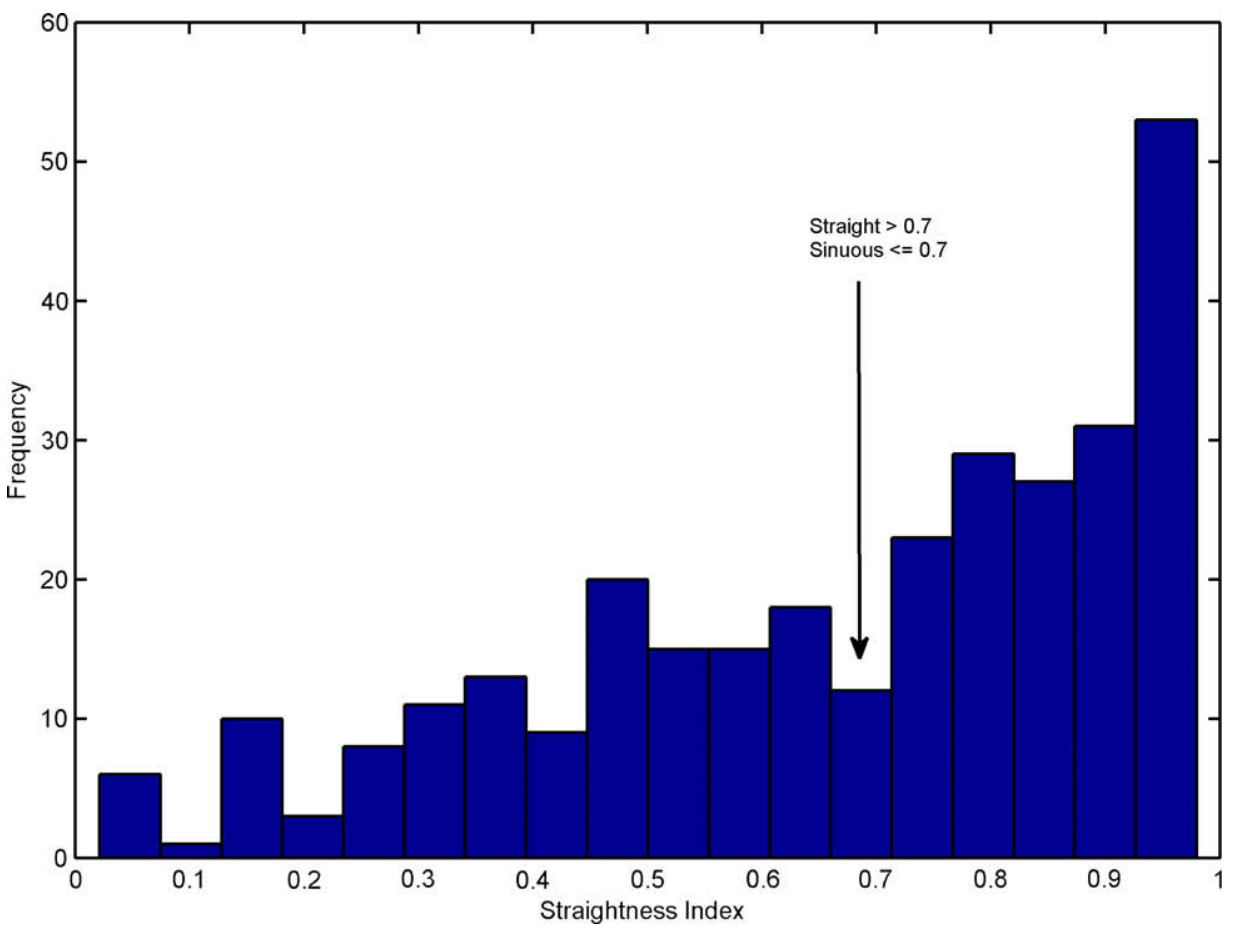

Fig. 3. Histogram of straightness indices calculated for all track segments. Break point for straight vs. sinuous track segments is indicated with arrow.

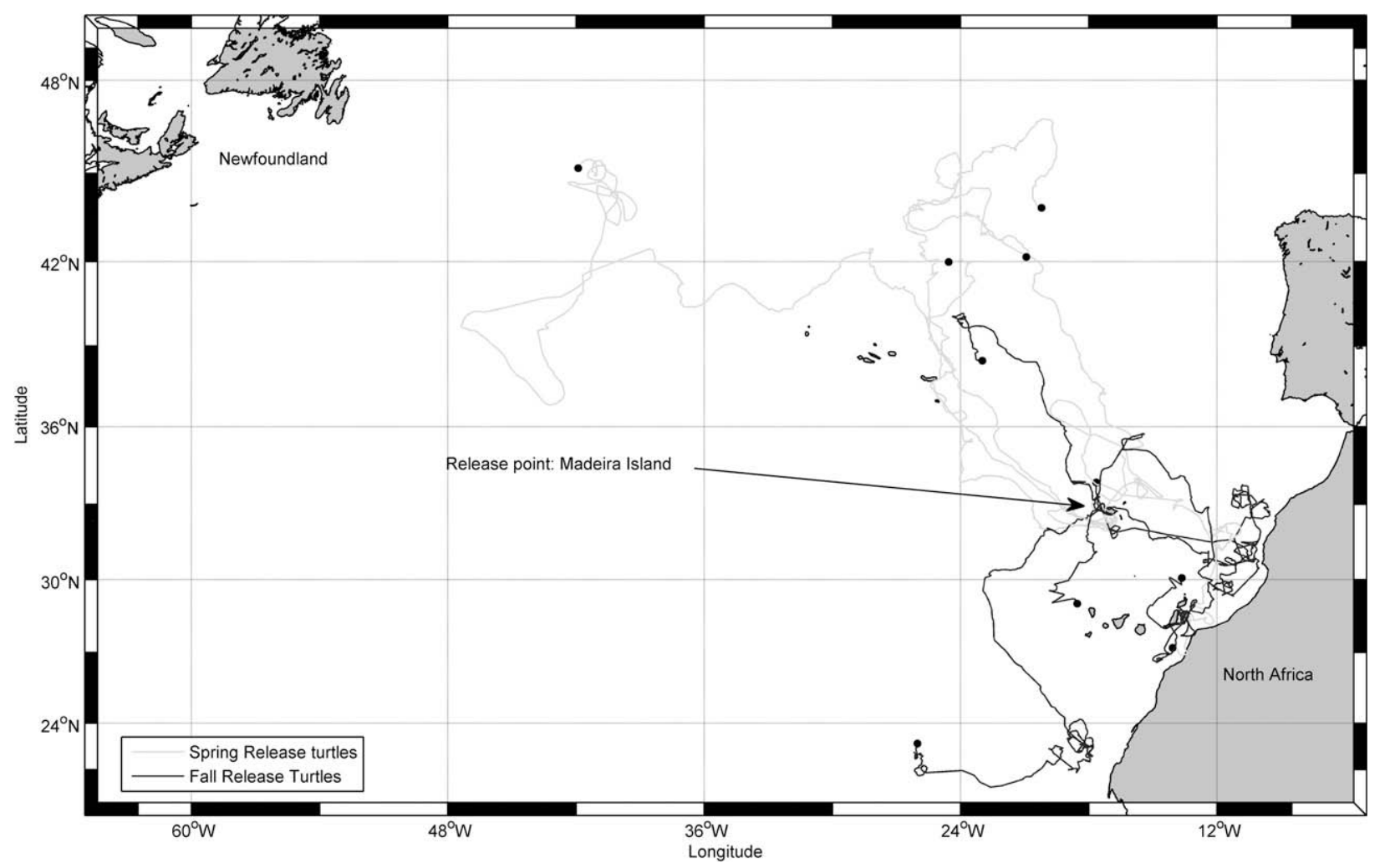

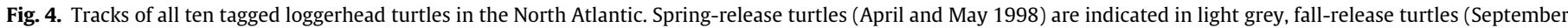
1998) in black. Animals were released in waters near Madeira.

reduced model (Reduced model 2) where we eliminated circular standard deviation, the AIC value was less than two points lower than that of the final model (Table 2). Because the circular standard deviation (s) was significant in the final model, we chose to include it even though the most reduced model had a slightly lower AIC. 


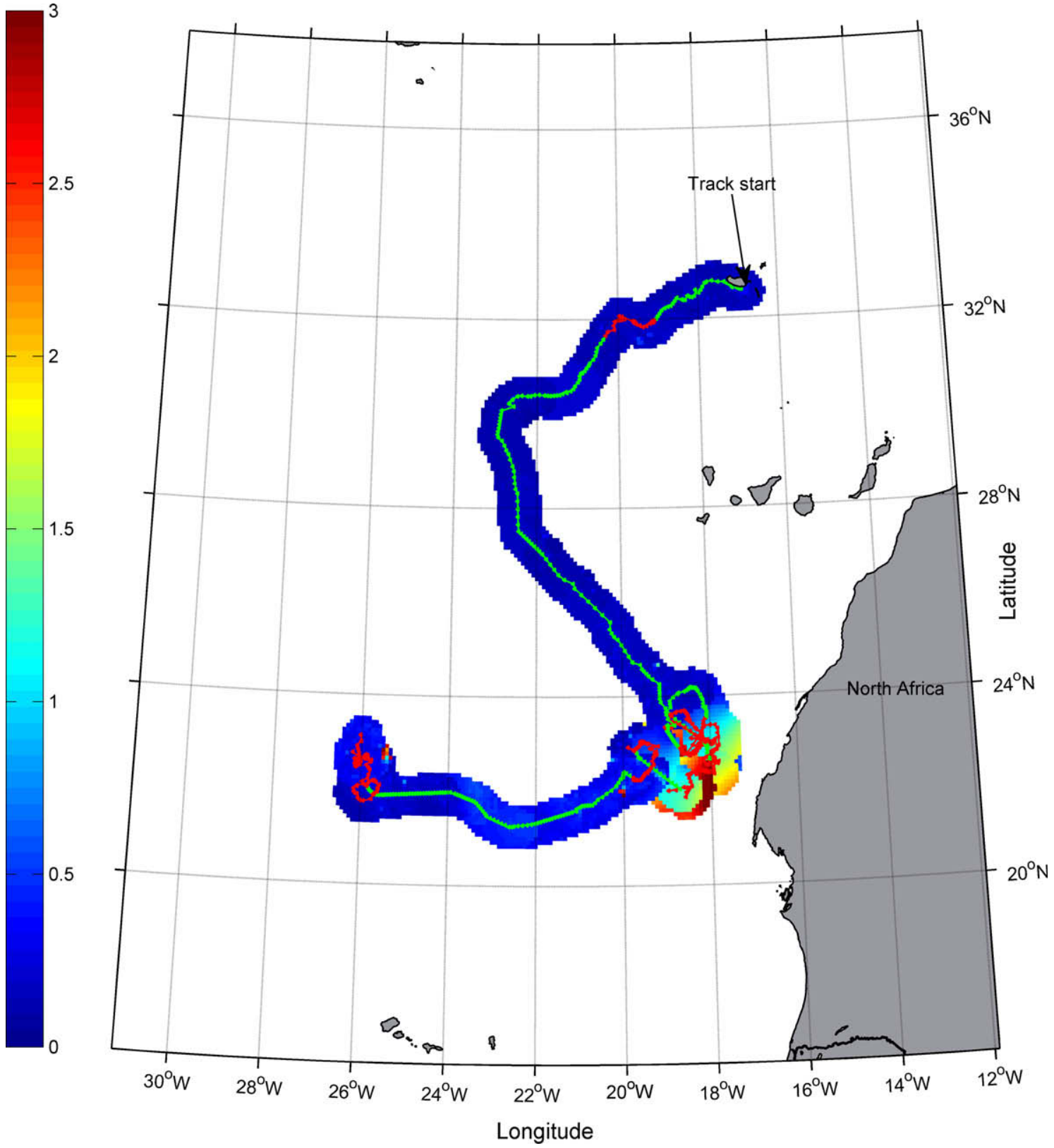

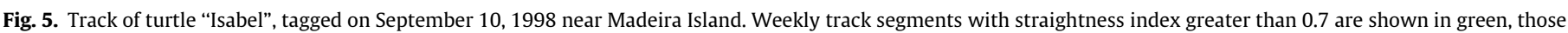

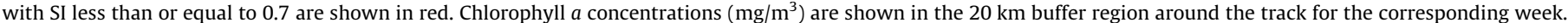

Table 2

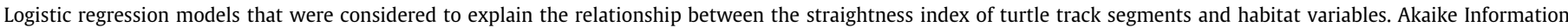
Criterion (AIC) is listed for each model. The final model selected is shown in bold.

\begin{tabular}{|c|c|}
\hline Model & AIC \\
\hline Full model: $\beta_{1} \log ($ chlorophyll $a)+\beta_{2}$ (bathymetry) $+\beta_{3} \log (\mathrm{SST})+\beta_{4}(s)+\beta_{5}$ (turtle $)+\beta_{6}($ spring/fall $)$ & 957.1 \\
\hline Reduced model 1: $\beta_{1} \log ($ chlorophyll $a)+\beta_{2}$ (bathymetry) $+\beta_{3} \log (\mathrm{SST})+\beta_{4}(s)+\beta_{5}$ (turtle) & 955.1 \\
\hline Final model: $\beta_{1} \log ($ chlorophyll $a)+\beta_{2}$ (bathymetry) $+\beta_{3} \log (\mathrm{SST})+\beta_{4}(s)$ & 953.4 \\
\hline Reduced model 2: $\beta_{1} \log ($ chlorophyll $a)+\beta_{2}$ (bathymetry) $+\beta_{3} \log (\mathrm{SST})$ & 952.9 \\
\hline
\end{tabular}

\subsection{Logistic regression of straightness index on marine habitat variables}

The best fit logistic regression model with straightness index as a response: $\operatorname{logit}(\pi)=\beta_{0}+\beta_{1} \log ($ chlorophyll $a)+\beta_{2}$ (bathymetry) $+\beta_{3} \log (\mathrm{SST})+\beta_{4}(s)$ included four variables, all of which were significant at the 0.05 level (Table 3 ). A strong negative relationship existed between SI and log-transformed chlorophyll $a$; straighter tracks were in lower chlorophyll areas, and more sinuous tracks were in higher chlorophyll areas. In contrast, SI increased when animals encountered areas of higher SST as well as when they moved over deeper areas of the ocean. Although statistically significant, the effect of circular standard deviation on the probability of having a straight-track segment is, however, very small (see $\beta_{4}$ value in 
Table 3

Logistic regression for tracking data $(n=304)$. Significant $p$-values for the regression are marked with an asterisk ( $*$ ). Regression equation: $\operatorname{logit}(\pi)=\beta_{0}+\beta_{1} \log$ (chlorophyll a) $+\beta_{2}$ (bathymetry) $+\beta_{3} \log (\mathrm{SST})+\beta_{4}$ (s: circular standard deviation of current).

\begin{tabular}{lccll}
\hline Coefficients & Estimate & Z-statistic & $\begin{array}{l}p \text {-Value } \\
\text { (Wald's) }\end{array}$ & $\begin{array}{l}\text { Standard } \\
\text { error }\end{array}$ \\
\hline (Intercept) & -8.8 & -3.7 & $0.0002^{*}$ & 2.34 \\
$\log \left(\right.$ chlorophyll) $\left(\beta_{1}\right)$ & -0.55 & -3.6 & $0.001^{*}$ & 0.17 \\
$\log \left(\right.$ bathymetry) $\left(\beta_{2}\right)$ & 0.70 & 2.61 & $0.008^{*}$ & 0.26 \\
$\log (\mathrm{SST})\left(\beta_{3}\right)$ & 0.69 & 2.27 & $0.025^{*}$ & 0.31 \\
$\beta_{4}(s)$ & 0.009 & 2.15 & $0.049^{*}$ & 0.0047 \\
\hline
\end{tabular}

Table 3). During the straighter track segments, the animal was somewhat more likely to be moving through areas with diffuse geostrophic current vectors. Wald's test provides a $p$-value for the significance of the predictive power of logistic regression coefficients at the 0.05 level (Table 3 ).

\section{Discussion}

We show clear relationships between the behavior of individual animals, as evidenced by track sinuosity, and the characteristics of the surface ocean around those tracks. All ten of the tracked animals exhibited behavior akin to foraging in high chlorophyll areas and shallower parts of the ocean than in deeper, low chlorophyll areas. The same is true for warmer areas where track segments are straighter, as demonstrated by the generalized linear model of the entire data set (Table 2). In addition, the circular standard deviation of the current around track segments was related to the sinuosity of tracks, with straighter tracks more often passing through more disperse current regions. Track sinuosity also increased in shallower areas. This link is due, most likely, to the time spent by individual animals over seamounts and over the shelf regions, both locations where upwelling often occurs. The positive relationship between high chlorophyll water masses and increased sinuosity of tracks suggests that these animals prefer those areas to lower chlorophyll areas for foraging. While turtles do not directly consume chlorophyll $a$, many of their preferred prey items may be more abundant in regions with higher chlorophyll.

Assuming that sinuosity is an indicator of foraging behavior, the negative correlation between bathymetry and straightness index is consistent with the foraging of many marine animals at seamounts and shelf regions (Guinet et al., 2001; Burns et al., 2004; Suryan et al., 2006). The relationship we found between increased sinuosity and high chlorophyll concentration is supported by the fact that many animals forage in areas of persistently high chlorophyll, which are sometimes related to bathymetric anomalies (Yen et al., 2004; Palacios et al., 2006). These results also support findings that Pacific juvenile loggerhead turtles seek out dynamic, high chlorophyll regions for foraging (Polovina et al., 2004, 2006).

Although our data do not conclusively prove that animals are foraging in high chlorophyll or high-relief bathymetric regions, the relationship between simple movements and easily observed marine environmental variables such as bathymetry, chlorophyll $a$, and SST can be a useful tool. It is not usually possible to survey large regions of the ocean for prey items of pelagic megafauna, so some kind of proxy must be used to infer the location of foraging grounds in the absence of concrete information about prey distributions. By examining how animals change their behavior relative to oceanographic variables, hypotheses about the location of foraging grounds can be generated, and these hypotheses can be considered when making conservation decisions regarding critical habitat for pelagic megafauna. We suggest that when planning conservation areas for loggerhead turtles, both high-upwelling coastal regions and high-relief bathymetric areas like seamounts be considered due to their importance as foraging areas. This kind of analysis can also be repeated on the same population on an annual or multi-annual basis to determine whether changes in foraging preferences are influenced by climate variability over longer time periods.

The logistic regression of the entire tracking dataset indicated that straighter track segments were more likely to occur in areas where the geostrophic currents were less directed. This suggests that ocean currents played a part in determining the movement of these ten animals, and that animal movement may be dictated both by the surrounding current and by other oceanographic variables. However, we did not include Ekman current in this analysis, as Ekman current is a relatively small component of surface current in the North Atlantic (Flatau et al., 2003). It is possible that including the measure of total surface current in the regression, or subtracting the current and performing the same regression procedure on current-corrected tracks, would be worthwhile (Gaspar et al., 2006); however, in this study we were interested in the trajectory that the animals actually followed and the environment they occupied while doing so, as opposed to the trajectories they would have followed in a motionless ocean.

In conclusion, this study provides valuable insight into the quantitative relationship between the marine environment and the behavioral patterns of individuals. This type of analysis can easily be applied to the tracks of other long-ranging marine vertebrates, and can assist in the assessment of available habitat on a basin-wide scale. This will add to our existing knowledge and has important implications in risk assessment for potential fisheries interactions.

\section{Acknowledgements}

We thank Renato Barradas for his valuable assistance with the field component of this work and Alan B. Bolten for the training on satellite tag application. This study was funded by the Life Nature project (Life96Nat/P/3019) and by the Pelagic Fisheries Research Program, the Marine Technology Society (Charles $\mathrm{H}$. Bussmann grant), and the Hatfield Marine Science Center (Reynolds grant). We would also like to thank the OSU Department of Fisheries and Wildlife for an Oregon Laurels scholarship and a Scott scholarship. Publication of this paper was supported, in part, by the Thomas G. Scott Achievement Grant. We want to thank Dr. Martin Saraceno, Dr. Kate Mansfield and Dr. Rob Suryan for invaluable advice. Finally, thanks to Dr. Molly Lutcavage, Dr. Chris Wilson, Steve and Cindy McCarthy, and to Max.

\section{References}

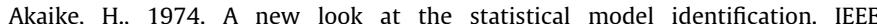
Transactions on Automatic Control 19, 7.

ARGOS, 1996. User's Manual. CLS/Service ARGOS, Toulouse, France.

Balazs, G.H., Miya, R.K., Beavers, S.C., 1996. Procedures to attach a satellite transmitter to the carapace of an adult green turtle, Chelonia mydas. NOAA technical memorandum NMFS-SEFSC-387, Miami, FL, National Marine Fisheries Service, Southeast Fisheries Science Center, pp. 21-26.

Barbraud, C., Weimerskirch, H., 2001. Emperor penguins and climate change. Nature 411, 183-186.

Batschelet, E., 1981. Circular Statistics in Biology. Academic Press, 111 Fifth Ave. New York, NY 10003. 388pp.

Baumgartner, M.F., Mate, B.R., 2005. Summer and fall habitat of North Atlantic right whales (Eubalaena glacialis) inferred from satellite telemetry. Canadian Journal of Fisheries and Aquatic Sciences 62, 527-543.

Bearman, G. (Ed.), 2001. Ocean Circulation. Open University/ButterworthHeinmann, Walton Hall, Milton Keynes MK76AA/Oxford.

Benhamou, S., 2004. How to reliably estimate the tortuosity of an animal's path: straightness, sinuosity, or fractal dimension? Journal of Theoretical Biology 229, 209-220.

Bovet, P., Benhamou, S., 1988. Spatial analysis of animals' movements using a correlated random walk model. Journal of Theoretical Biology 131, 419-433. 
Burns, J.M., Costa, D.P., Fedak, M.A., Hindell, M.A., Bradshaw, C.J.A., Gales, N.J., McDonald, B., Trumble, S.J., Crocker, D.E., 2004. Winter habitat use and foraging behavior of crabeater seals along the Western Antarctic Peninsula. Deep-Sea Research Part II 51, 2279-2303.

Dellinger, T., Freitas, C., 1999. Movements and diving behaviour of pelagic stage loggerhead sea turtles in the North Atlantic: preliminary results obtained through satellite telemetry. In: 19th Annual Sea Turtle Symposium, South Padre Island, Texas, USA, pp. 155-157.

Eckert, S.A., 2006. High-use oceanic areas for Atlantic leatherback sea turtles (Dermochelys coriacea) as identified using satellite telemetered location and dive information. Marine Biology 149, 1257-1267.

Flatau, M.K., Talley, L., Niiler, P.P., 2003. The North Atlantic oscillation, surface current velocities, and SST changes in the subpolar North Atlantic. Journal of Climate 16, 2355-2369.

Freitas, C., Kovacs, K.M., Lydersen, C., Ims, R.A., 2008. A novel method for quantifying habitat selection and predicting habitat use. Journal of Applied Ecology 45 1213-1220.

Gaspar, P., Georges, J.Y., Fossette, S., Lenoble, A., Ferraroli, S., Le Maho, Y., 2006 Marine animal behavior: neglecting ocean currents can lead us up the wrong track. Proceedings of the Royal Society B - Biological Sciences. doi:10.1098| rspb.2006.3623.

Guinet, C., Dubroca, L., Lea, M.A., Goldsworthy, S., Cherel, Y., Duhamel, G., Bonadonna, F., Donnay, J.P., 2001. Spatial distribution of foraging in female Antarctic fur seals Arctocephalus gazella in relation to oceanographic variables: a scale-dependent approach using geographic information systems. Marine Ecology - Progress Series 219, 251-264.

Gutenkunst, R., Newlands, N., Lutcavage, M., Edelstein-Keshet, L., 2007. Inferring resource distributions from Atlantic bluefin tuna movements: an analysis based on net displacement and length of track. Journal of Theoretical Biology 245 (2), 243-257.

Hawkes, L.A., Broderick, A.C., Coyne, M.S., Godfrey, M.H., Lopez-Jurado, L.F., LopezSuarez, P., Merino, S.E., Varo-Cruz, N., Godley, B.J., 2006. Phenotypically linked dichotomy in sea turtle foraging requires multiple conservation approaches. Current Biology 16, 990-995.

Hays, G.C., Ekesson, S., Godley, B., Luschi, P., Santridian, P., 2001. The implications of location accuracy for the interpretation of satellite-tracking data. Animal Behaviour 61, 1035-1040.

Hill, S., Burrows, M.T., Hughes, R.N., 2000. Increased turning per unit distance as an area-restricted search mechanism in a pause-travel predator, juvenile plaice, foraging for buried bivalves. Journal of Fish Biology 56 (6), 1497-1508.

Hull, C.L., Hindell, M.A., Michael, K., 1997. Foraging zones of royal penguins during the breeding season, and their association with oceanographic features. Marine Ecology - Progress Series 153, 217-228.

Hyrenbach, K.D., Forney, K.A., Dayton, P.K., 2000. Marine protected areas and ocean basin management. Aquatic Conservation - Marine and Freshwater Ecosystems 10, 437-458.

James, M.C., Eckert, S.A., Myers, R.A., 2005. Migratory and reproductive movements of male leatherback turtles (Dermochelys coriacea). Marine Biology 147, 845853.

James, M.C., Ottensmeyer, C.A., Eckert, S.A., Myers, R.A., 2006. Changes in diel diving patterns accompany shifts between northern foraging and southward migration in leatherback turtles. Canadian Journal of Zoology - Revue Canadienne De Zoologie 84, 754-765.

Jonsen, I.D., Myers, A., Flemming, J.M., 2005. Robust state-space modeling of animal movement data. Ecology 84, 3055-3063.

Kobayashi, D.R., Polovina, J.J., Parker, D.M., Kamezaki, N., Cheng, I.-J., Uchida, I., Dutton, P.H., Balazs, G.H., 2008. Pelagic habitat characterization of loggerhead sea turtles, Caretta caretta, in the North Pacific Ocean (1997-2006): insights from satellite tag tracking and remotely sensed data. Journal of Experimental Marine Biology and Ecology 356 (1-2), 96-114.

Maerell, A., Ball, J.P., Hofgaard, A., 2002. Foraging and movement paths of female reindeer: insights from fractal analysis, correlated random walks, and Levy flights. Canadian Journal of Zoology - Revue Canadienne de Zoologie 80, 854865 .

Newlands, N.K., Lutcavage, M.E., Pitcher, T.J., 2004. Analysis of foraging movements of Atlantic bluefin tuna (Thunnus thynnus): individuals switch between two modes of search behaviour. Population Ecology 46, 39-53.

Palacios, D.M., Bograd, S.J., Foley, D.G., Schwing, F.B., 2006. Oceanographic characteristics of biological hot spots in the North Pacific: a remote sensing perspective. Deep-Sea Research Part II - Topical Studies in Oceanography 53, 250-269.

Pinaud, D., Weimerskirch, H., 2007. At-sea distribution and scale-dependent foraging behaviour of petrels and albatrosses: a comparative study. Journal of Animal Ecology 76, 9-19.

Polovina, J.J., Balazs, G.H., Howell, E.A., Parker, D.M., Seki, M.P., Dutton, P.H., 2004. Forage and migration habitat of loggerhead (Caretta caretta) and olive ridley (Lepidochelys olivacea) sea turtles in the central North Pacific Ocean. Fisheries Oceanography $13,36-51$.

Polovina, J., Uchida, I., Balazs, G., Howell, E.A., Parker, D., 2006. The Kuroshio extension bifurcation region: a pelagic hotspot for juvenile loggerhead sea turtles. Deep-Sea Research Part II, 326-339.

Roweis, S., Ghahramani, Z., 1999. A unifying review of linear gaussian models. Neural Computation 11, 305-345.

Royer, F., 2008. Personal communication.

Royer, F., Lutcavage, M., 2008. Filtering and interpreting location errors in satellite telemetry of marine animals. Journal of Experimental Marine Biology and Ecology 359 (1), 1-10.

Seminoff, J.A., Zarate, P., Coyne, M., Foley, D.G., Parker, D., Lyon, B.N., Dutton, P.H., 2008. Post-nesting migrations of Galapagos green turtles Chelonia mydas in relation to oceanographic conditions: integrating satellite telemetry with remotely sensed ocean data. Endangered Species Research 4, 57-72.

Sibert, J.R., Musyl, M.K., Brill, R.W., 2003. Horizontal movements of bigeye tuna (Thunnus obesus) near Hawaii determined by Kalman filter analysis of archival tagging data. Fisheries Oceanography 12, 141-151.

Smith, S.R., Bourassa, M.A., Sharp, R.J., 1999. Establishing more truth in true winds. Journal of Atmospheric and Oceanic Technology 16, 939-952.

Suryan, R.M., Sato, F., Balogh, G.R., Hyrenbach, K.D., Sievert, P.R., 2006. Foraging destinations and marine habitat use of short-tailed albatrosses: a multi-scale approach using first-passage time analysis. Deep-Sea Research Part II 53, 370386.

Vincent, C., McConnell, B.J., Ridoux, V., Fedak, M.A., 2002. Assessment of ARGOS location error from satellite tags deployed on captive gray seals. Marine Mammal Science, 156-166.

Wanless, S., Frederiksen, M., Daunt, F., Scott, B.E., Harris, M.P., 2007. Black-legged kittiwakes as indicators of environmental change in the North Sea: evidence from long-term studies. Progress in Oceanography 72, 30-38.

White, G.C., Garrott, R.A., 1990. Analysis of Wildlife Radio-tracking Data. Academic Press.

Yen, P.P.W., Sydeman, W.J., Hyrenbach, K.D., 2004. Marine bird and cetacean associations with bathymetric habitats and shallow-water topographies: implications for trophic transfer and conservation. Journal of Marine Systems $50,79-99$.

Zar, J.H., 1999. Biostatistical Analysis. Prentice Hall, Upper Saddle River, New Jersey. 663. 